Portland State University

PDXScholar

5-18-1976

\title{
Evaluation of the Institute of Transportation Engineers Program for School Pedestrian Crossing
}

Nabil Shafiq Hamadeh

Portland State University

Follow this and additional works at: https://pdxscholar.library.pdx.edu/open_access_etds

Part of the Automotive Engineering Commons

Let us know how access to this document benefits you.

\section{Recommended Citation}

Hamadeh, Nabil Shafiq, "Evaluation of the Institute of Transportation Engineers Program for School Pedestrian Crossing" (1976). Dissertations and Theses. Paper 4045.

https://doi.org/10.15760/etd.5929

This Thesis is brought to you for free and open access. It has been accepted for inclusion in Dissertations and Theses by an authorized administrator of PDXScholar. Please contact us if we can make this document more accessible: pdxscholar@pdx.edu. 
AN ABSTRACT OF THE THESIS OF Nabil S. Hamadeh fox the Master of Scfence in Applied Science presented May 18, 1976.

Title: Evaluation of the Institute of Transportation Engineers Program for School Pedestrian Crossing

APPROVED BY MEMBERS OF THE THESIS COMMITTEE:

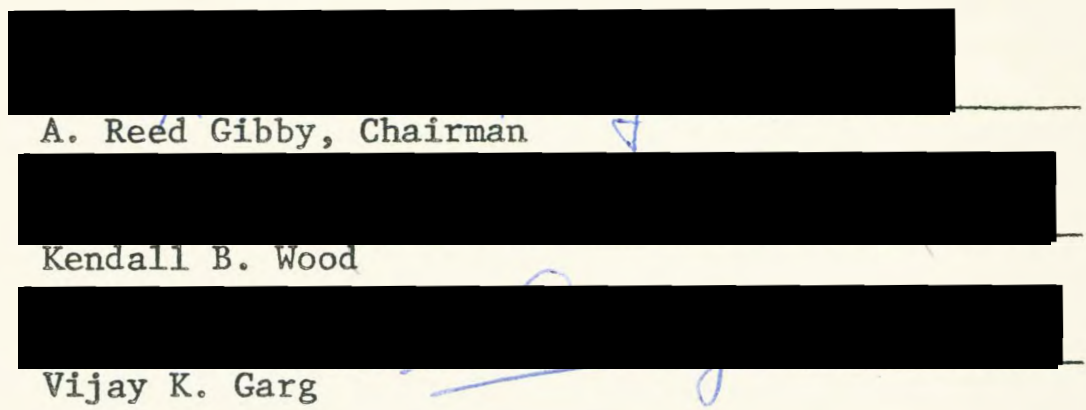

The Technical Council of the Institute of Transportation Engineers (ITE) developed a program for school crossing protection. The intent of this thesis is to evaluate the ITE program within the context of those programs developed by other agencies throughout the nation. Research materials were obtained from the appropriate Federal, state, local and other agencies through papers, articles, reports and correspondence. Upon the analysis of these sources, the ITE program was found to be deficient in several ways. Recommendations for modifying the program which are set forth herein include a revision of the ITE program including the school route map, clarification of technical terminology, incorpoxation of a sound criteria for selecting the appropriate protective devices and/or measures, establishing a priority system, deletion of portable school 
signs, identification of funding sources, and establishing additional warrants for the installation of traffic control devices. 
EVALUATION OF THE INSTITUTE OF TRANSPORTATION ENGINEERS PROGRAM FOR SCHOOL PEDESTRIAN CROSSING

$$
\text { by }
$$

NABIL SHAFIQ HAMADEH

\begin{abstract}
A thesis submitted in partial fulfillment of the requirements for the degree of
\end{abstract}

\author{
MASTER OF SCIENCE \\ IN \\ APPLIED SCIENCE
}

Portland State University

1976 


\section{TO THE OFFICE OF GRADUATE STUDIES AND RESEARCH:}

The members of the Committee approve the thesjs of Nabil $S$. Hamadeh presented May 18, 1976.

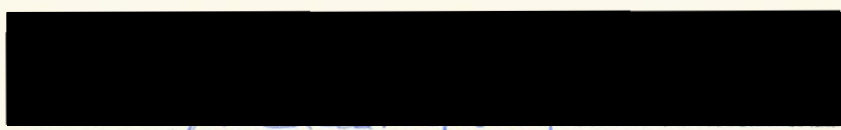

A. Reed Gibby, Chairman ]

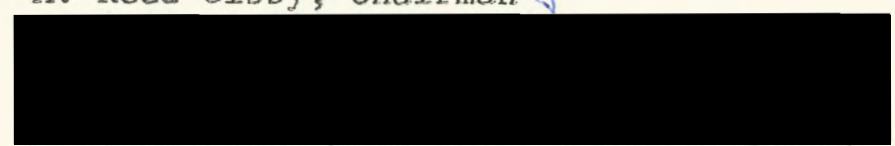

Kenda11 B. Wood

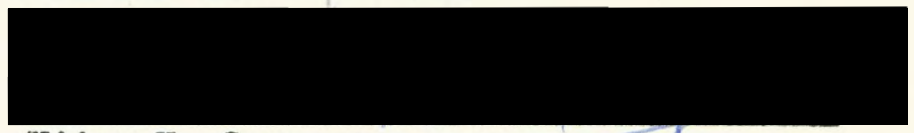

Vijay K. Garg

APPROVED :

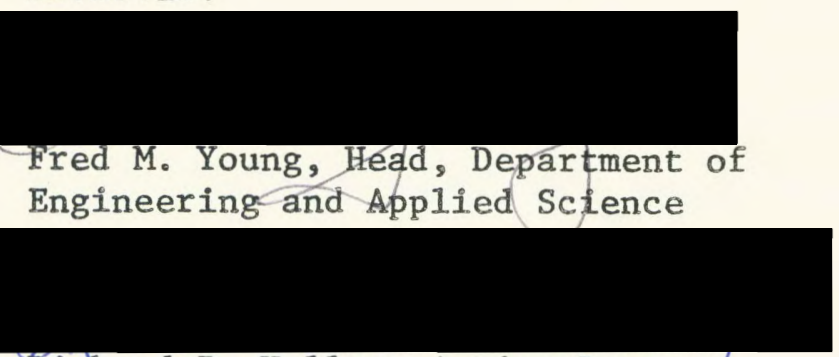

Richard B. Halley, Acting Dean Graduate Studies and Research 
TABLE OF CONTENTS

PAGE

PREFACE AND ACKNOWLEDGMENTS $\ldots \ldots \ldots \ldots \ldots \ldots \ldots \ldots$ ifi CHAPTER

I INTRODUCTION $\ldots \ldots \ldots \ldots \ldots \ldots \ldots \ldots \ldots \ldots \ldots \ldots \ldots \ldots \ldots$

II THE ITE PROGRAM ..................... 4

II OTHER SCHOOL CROSSING PROGRAMS AND PRACTICES...... 14

Federal Programs ..................... 14

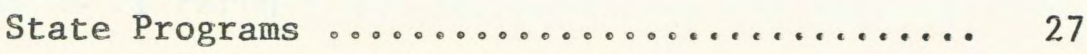

Loca1 Programs ................... 30

Miscellaneous Programs $\ldots \ldots \ldots \ldots \ldots \ldots \ldots . \ldots 40$

IV INADEQUACIES IN THE ITE PROGRAM ........... 50

V CONCLUSIONS AND RECOMMENDATIONS ............ 55

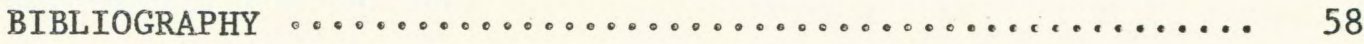


PREFACE AND ACKNOWLEDGMENTS

With the increased use of motor vehicles, the safety of young children crossing streets or highways on their way to and from schooI. has been the concern of the community leaders, traffic engineers, parents, school officials, and law enforcement officers. As school programs developed in local communities, a need for uniform practices was recognized as wel1 as other areas of traffic control. In 1930, three national organizations, the American Automobile Association, the National Congress of Parents and Teachers, and the National Safety Council, formulated rules entitled "Standard Rules for the Operation of School Boy Patrols." Since then, numerous articles and policies have been published on school traffic safety by authorities from traffic engineering, enforcement, educational and other organizations throughout the nation.

The purpose of this study is to evaluate the protection program recommended by the ITE [Institute of Transportation (previousIy Traffic) Engineers] and synthesize other available programs adopted by FederaI, state, and local agencies. An analytical comparison wiI be conducted between the said programs and apparent deficiencies in the ITE program will be identified. Finally recommendations for the corrective measures to fill in any deficiencies will be specified.

I am indebted to my thesis committee for ideas and suggestions which made this study possible. Appreciation is also expressed to all of the following well-known traffic engineers who contributed their time and talents: Chris E. Ena of VTN Consultants Irnne, California 
and James Johnson of the City of Ames, Iowa.

Finally I wish to thank my wife for the encouragement and patience she provided throughout the duration of my course work and the preparation of this thesis. 
CHAPTER I

\section{INTRODUCTION}

One of the most pressing and controversial problems which traffic engineering and enforcement agencies are faced with today concerns the safety of children on their way to and from school. ${ }^{I}$ This is attributed to the vast development of motor transportation over the years which brought tremendous changes to our cities. Until some 40 years ago, urban populations were concentrated in limited areas because of the restrictions in movement characteristic of rail, pedestrian and horsedrawn systems. The combined effects of the freedom of movement offered by automobile transportation and the population shift from rural to urban areas have brought an explosion to the cities. This trend began after World War $I$ and has rapidly accelerated since WorId War II. Today our urban areas are assuming an entirely new form, geared. fncreasingly to motor vehicle transportation. Vehicular traffic volumes and miles traveled are increasing steadily and pedestrian involvement fn. traffic becomes a major consideration in many situations which confront the traffic engineers. The question that arises is how the school traffic safety problem can be best addressed with a minimum of disruption and cost, and with a maximum of effectiveness. The National Safety Council estimates that each year over 14,000 school children suffer traffic accidents. Nearly two thirds involving youngsters walk-

${ }^{1}$ Institute of Transportation Engineers (1), pg. 5 
ing to or from school. ${ }^{1}$ No official would dare say that he isn't concerned with safety of school children, but many seem to be wiliing to accept a certain number of injuries and deaths while giving attention to such "largex problems" as smooth traffic flow."

Traffic engineers and educators are continuing to seek improved protection for school children using crossing protection provided by the responsible public agencies. The need was to consolidate professional engineering techniques on the subject of school crossing protection by utilizing appropriate laws, engineering judgment and procedures that are uniformly applied to each location. PubIic acceptance of protection programs and respect for laws will then be developed. Adherence to uniform and consistent practices will increase child safety as weII. as the respect of the motorists and the enforcement agencies.

This thesis will outline the ITE program for school crossing protection and shed light on several other programs, proposed by Federal, state, local and other agencies, in order to run a comparative anaijysis that would disclose any deficiencies of the ITE program, such that recommendations may be offered to provide corrective adjustments which would eliminate these deficiencies. The ITE program for schooI crossing protection prepared by the ITE Technical Council and adopted on August 12. 1962 by the Board of Directors as a "Recommended Practice" of the Institute of Transportation Engineers, is the subject matter of Chapter II. Various other programs, grouped and discussed under Federal, state, local and miscellaneous will be discussed in Chapter III. 
Chapter IV will be devoted for comparative analysis of the availabie programs versus the ITE Protection program, and finaliy Chapter V wiII close this study with a sumary of conclusions together with recommendations proposed for incorporation into the ITE program. 
THE ITE PROGRAM

The ITE program is a school crossing protection program prepared and adopted by the Institute of Transportation Engineers. It was developed to provide a general procedure for the logical selection of those locations where crossing hazards exist and the appropriate measures of traffic control. The ITE program consists of sir basic steps, organization of a school traffic safety committee, development of a school route plan, study of the school crossings where apparent hazards exist, analysis of the need for school crossing protection, selection of the appropriate measures for locations where control is needed, and selection of the standard devices needed to carry out the protection program。

\section{Step 1 - Organize a School Traffic Safety Committee}

The School Traffic Safety Committee is to be formed of governmental and school board officials with executive authority to carry out any plans so proposed by the committee. Specifically, the members of the Committee should include the traffic engineer, the head of the police traffic division, and school representatives. The manager of the local safety council, the presidents of parent-teacher organizations, and representatives of other interested organizations should be invited to serve on the Committee in an advisory capacity. The functions of the Committee can be summarized as follows: 
1. Establish policies and procedures.

2. Review and approve the various phases of the school traffic safety program.

3. Review and handle complaints and requests.

4. Establish priorities on projects.

5. Promote good public relations.

6. Take immediate action to correct emergency school. traffic safety problems. 1

Step 2 - Develop a School Route Plan

The School Traffic Safety Committee should consider a selection of school route plans for each school of concern. This plan should depict all streets, the school, existing traffic controls and the proposed school routes to be used by children. All parties concerned should. have the opportunity to examine the said plan, and upon approval, the school route plan will be officially adopted by the School Traffic Safety Committee. The school route plan should be designed in such a manner that maximum protection for children is secured at the Iowest cost to the taxpayer. This could be accomplished by fuII utilfzation of the protection already provided by the existing traffic controlss Which may occasionally requixe children to walk Jonger distances to avoid potential hazards. School children should be introduced to the school route plan with clear instructions as to its purpose and use. Every child should be provided with a copy of the plan which could be taken home and looked over by parents for further action on their part.

Field checks should be conducted along school routes to assure their proper usage. This could be accomplished on an annual basis by parent-teacher organizations or by volunteer mothers. Any defects found

${ }^{1}$ Institute of Transportation Engineers (1)s pg. 7 
should be reported directly to the School Traffic Safety Committee so that the latter can take prompt corrective action.

The school route plan should be reviewed every year before schooIs begin with due consideration to any possible modifications deemed. necessary because of changes in the school district boundarfes, highway or traffic patterns, or installation of new controls.

\section{Step 3 - Study the School Crossings Where Apparent Hazards Exist}

During the preparation of the school route plan in Step 2, circumstances or situations might arise such that the selected route wiJI require children to cross a major highway or other substantial hazard. These crossings are to be studied and analyzed by a systematic procedure leading to recommendations with associated priorities for the application of the special traffic controls or measures discussed Iater in Step 5. The following assumptions are the basis in the ITE recommended procedure for study:

1. Alternating gaps and blockades are formed in the vehicular traffic stream in a pattern peculiar to each Iocation. This requires an analysis of hazard at each Iocation.

2. Pedestrians will wait a reasonable time for an adequate gap in traffic before crossing a street.

3. It is assumed that there is no traffic control signal at the location under study. However, if such signal has been installed, Appendix B of the ITE program should be consulted before proceding with items 2 and 3 of the field studies listed below. 1

Items to be determined from field studies are:

1. The number of rows of pedestrians walking five abreast at the crossing under study $(\mathrm{N})$.

2. The width (in feet) of the pavement to be crossed by the group of pedestrians (W). 1

\footnotetext{
${ }^{1}$ Institute of Transportation Engineers (1), pg. 10
} 
3. The actual pedestrian delay time (as a percent of the total survey time) created by the traffic flow at the location under study (D). 1

\section{Step 4 - Analyze the Need for School Crossing Protection}

In analyzing the need for school crossing protection, two basic assumptions should be taken into consideration. First, chfidren may become impatient and attempt to cross the street during an inadequate gap, when the delay time between adequate gaps becomes excessive.

Second, when the number of adequate gaps in the traffic stream, during the period the children are using the crosswalk, is less than the number of minutes in that same period of time, the delay time between adequate gaps is to be considered excessive. Gaps less frequent than one per minute is considered unsatisfactory and thus require some form of traffic control which would secure the necessary gaps to alleviate the hazard.

In utilizing the three items determined from field studies in. Step 3, a crossing can be classified in one of the following categories:

1. No special form of protection or control is needed.

2 . Some special form of protection is needed. 2

This will be achieved from Figure I, by plotting the percent pedestrian. delay (D) on the horizontal axis and the width of street (W) on the vertical axis thus establishing a point in relation to the appropriate pedestrian group line $(N)$. If the point is to the left of the pedestrian group line in question, no special form. of traffic control will be needed

\footnotetext{
${ }^{1}$ Institute of Transportation Engineers (1), pg . 10

${ }^{2}$ Institute of Transportation Engineers (1), pg. 11
} 


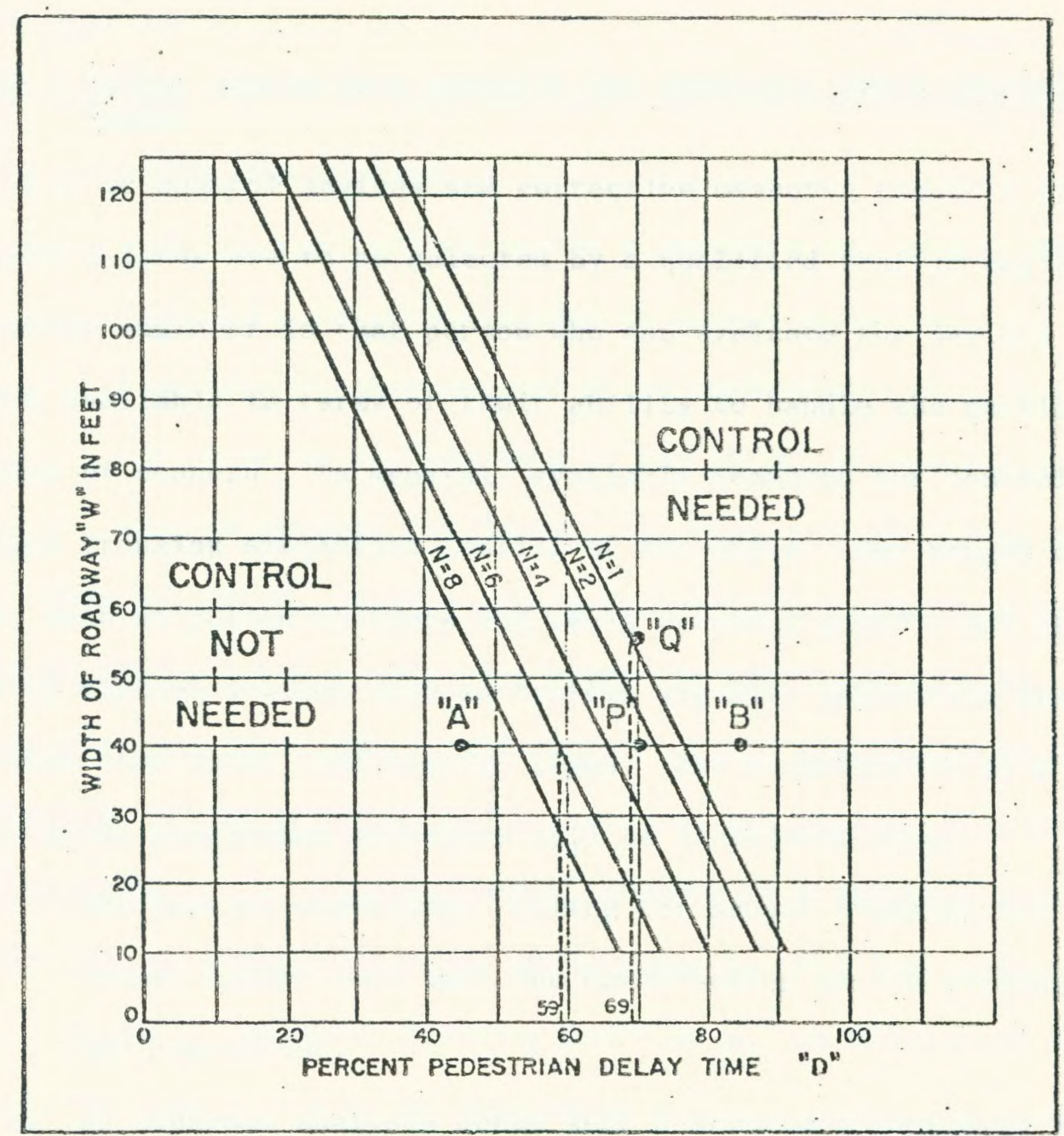

Figure 1. Determination of need for traffic control at school. crossings. 1

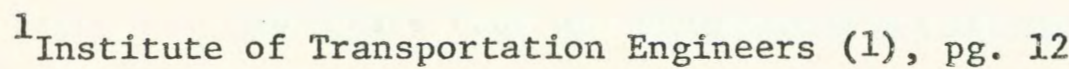


and the analysis of the location is complete. However, if the point falls on the right of the said line, then some special form of control will be needed.

\section{Step 5A - Select Appropriate Measures for Locations Where ControI is Needed}

Traffic control devices and corrective measures required to eliminate hazards are to be selected by a qualified traffic engineer. The traffic engineer is that person who can evaluate the devices and measures available in terms of their ability to handle the particular situation of concern. In general, available measures for controliing hazardous crossing situations consist of two types. One hinges on people, such as police officers and adult crossing guards, and the other relies on control devices such as traffic signals, pedestrian grade separation structures, and traffic signs. The construction of a pedestrian grade separation structure will be considered when:

1. The general conditions calling for school crossing are of permanent nature such that the construction of the structure is we11 justified.

2. An economic analysis deems such a structure necessary from a long-range standpoint.

3. The physical conditions of the location accommodate the structure from an engineering standpoint.

4. The cost of such an improvement does not affect available funds allocated for other essential measures of protection.

5. Such structure will render services, not only to school children, but also other pedestrians. 
6. The need for such a structure is not elfminated by possibie replanning of school routes or school districts.

Traffic signals may be considered as determined from Steps 3 and 4 provided that:

1. They are more practical and ecomomical than other types of protective devices.

2. Such an installation is not eliminated due to any probable replanning of school routes or school districts.

3. Signals installation will be in conformance with requirements set forth by Section 7D-4 of the Manual on Uniform Traffic Control Devices for Streets and Highways, 1971 Edition.

When warranted, signals should be designed to cause as Iittle delay as possible and to minimize hazard to vehicular traffic. Such design should account for the factors of signal visibility to motorists, suitability of the location to fit into the progression of a system of traffic signals, the desirability of pedestrian pushbutton signals, and the use of signals by other pedestrians in addition to chiddren.

The use of an adult crossing guard or police officer as determined. from Steps 3 and 4 should be considered if:

1. Justified from practical and economical standpoint.

2. Special hazards exist at some locations whether signalized or otherwise due to unusual conditions such as extreme fog, complicated intersections, heavy vehicular turning movement, and high vehicular approach speeds.

3. Protection is required only for a limited period of time due to a change in school routes or school districts. 
Step 5B - Select Appropriate "Assistance" Measures

Measures which cannot induce adequate gaps in traffic streams may be classified as "assistance" measures. These still belong to three types; namely, school student patrols, signs, pavement markings and. sidewalks. These measures should be selected based on recomendations proposed by a qualified traffic engineer.

School student patrols are applicable when supervision of children using a crossing is desired and conditions do not requixe a change in the actual direction of motor vehicle traffic by aduIts. The employment of this program requires the responsible officials to adhere to these procedures. The school authorities with the cooperation of the appropriate traffic enforcement agency should be in charge of organizing, training, and supervising the student patrol. The student patroI should limit its duty to directing or controlling children at the curb and allow them to cross the roadway only when adequate gaps in the traffic stream exist. Locations where traffic gap and other conditions permit the safe assignment of the student patrol should be determined by the traffic engineering authority. Assignment of student patroI should be restricted only to crossings in the school grounds vicinity. Signs are used to regulate, warn and inform motorists usfing the roadways in the vicinity of a school. All signs to be used shouId comply with the standards set forth in the "Manual on Uniform Traffic Control Devices for Streets and Highways" (MUTCD). Regulatory signs consist of speed limit signs which alert motorists of special speed regulatlons applied to a school zone as determined by the traffic engineering authority, and also parking signs which inform motorists of parking 
regulations established to alleviate hazards. Warning signs include school advance signs and school crossing signs. The instaliation of these signs should be controlled by individual furisdictions to avojd. using too many signs.

Pavement markings should be used to delineate pedestrian crossings in coordination with the regulatory and warning signs. These markings should also comply with the MUTCD. Good maintenance is required for pavement markings to insure theix effectiveness. Roadways adjacent to or in the vicinity of the school grounds, need special school pavement markings.

The construction of sidewalks or widened roadway shouIders wiII reduce hazards considerably to children walking along school routes. Good maintenance should be provided to these facilities to discourage children from walking on smoother surfaces in spite of the hazard.

Step 6 - Select the Standard Devices Needed to Carry Out the Protection Measures

The traffic control devices to be used for providing protection. against hazards should conform with the MUTCD. In addition, the following standards ${ }^{1}$ of the Institute of Transportation Engfneers may be of value:

Adjustable Face Vehicle Traffic Control SignaI Heads Pre-timed, Fixed Cycle, Traffic SignaI ControIIers Traffic-actuated, Traffic Signal Controllers and Detectors A Model Performance Specification for the Purchase of Thermoplastic Pavement Marking Materials Traffic Signal Lamps Adjustable Face Pedestrian Signal Heads ${ }^{1}$ 
In summary, this chapter itemizes the six major steps proposed by the ITE Program in selecting locations with potential hazards, and provides procedures for determining the appropriate protective measures which will eliminate these hazards or else reduce them. The steps include the organization of a safety committee, the school route maps analysis of hazardous sites, the need for school crossing protection, selection of the appropriate measures for traffic control, and finally the standard devices required to carry out the protection program. 
OTHER SCHOOL CROSSING PROGRAMS AND PRACTICES

While Chapter II was an outline of a program for schooI crossing protection recommended by the Institute of Transportation Engineers, this Chapter will serve as a survey of other programs developed by numerous agencies throughout the nation. These programs will be classified into four categories, Federal, state, Iocal, and miscellaneous programs.

\section{Federal Programs}

The MUTCD which is developed with the cooperation of the American Association of State Highway officials and the National Joint Committee on Uniform Traffic Control Devices, has been adopted on November I3, 1970 by the Federal Highway Administrator as a national standard for application on all classes of highways. Traffic control devices are aI.I signs, signals, pavement markings and devices placed on or adjacent to a street or highway by authority of a public body or official having jurisdiction to regulate, warn, or guide traffic. The need for uniform standards was recognized long ago, ${ }^{1}$ and because of the importance of uniform control device application on all roads and streets, Iocal jurisdictions are encouraged to follow, as closely as possible, future implementation schedules issued for state or Federal highway systems. The MUTCD sets forth the basic principles that govern the design and $1_{\text {MUTCD (3), pg. } 1}$ 
usage of traffic control devices as applied to any particular situation. Traffic control in school areas is quite essential, and regardiess of the school location, safe and effective craffic control can be best handled by the uniform application of realistic policies and standards developed through engineering studies. The effectiveness of traffic control measures could be greatly enhanced by fuII understanding of both the pedestrians as well as the motorists as to the need for traffic control and the ways in which these controls function for their benefit. The types of traffic control measures treated in the MUTCD and seIected for presentation herein include school route plan, traffic control devices, crossing supervision, and grade separated crossings.

School Route Plan: A school route plan ${ }^{I}$ for each school of concern is quite convenient in developing uniformity with regard to traffic controls. The planning and design criteria for developing schooI route plan and crossing control is inspired with its entirety from the ITE Protection Program presented in Chapter II of this thesis, and the typicaI plan offered by the MUTCD is identical to the one in the ITE program. The MUTCD recommends further consultation with the ITE Program in determining the frequency and adequacy of gaps in the vehicular traffic stream. All traffic control devices used in school areas are to conform to the applicable standards and specifications detailed in the MUTCD, a recommendation also made by the ITE Program.

Traffic Control Devices: Determination of the appropriate traffic control devices $^{1}$ at a particular location is made on the basis of an engineering study of the location. The MUTCD provides only standards, and by no means is meant to be a substitute for engineering judgment. 
Traffic control devices, however, should be maintained at high standards to ensure their legibility, visibility, and operability. They should. not bear any advertising or commercial message which is not pertinent to traffic control. Furthermore they should be approved by the appropriate authority having jurisdiction over the area in question for the purposes of regulation, warning, or guiding traffic. Typical traffic control devices discussed in the MUTCD include signs, markings, and traffic signals.

1. Signs - Design of signs based on uniformity would include shape, color, dimensions, symbols, wording, lettering, and illumination and reflectorization. Detailed drawings of the standard signs dipicted in the MUTCD can be furnished to interested agencies upon request from the U.S. Department of Transportation Federal Highway Administration. Minor changes intended to improve the signs are permitted provided that shapes, colors, and (where a word message is applicable) the wording are maintained. An increase above the standard sizes of signs is desirable at locations where legibility or emphasis is needed.

Signs lettering should be in the upper-case letters of the type approved by the National Joint Committee on Uniform Traffic ControI Devices and its sponsoring agencies. All signs should have a border of the same color as the legend at or just inside the edge. When the border is darker than the background, it should be set in from the edge, otherwise, the border should extend to the edge of the plate. 
Signs are to be placed in positions where they can be most effective without affecting lateral clearances or sight distances. They should have a maximum practical clearance from the edge of the traveled way for safety purposes, and portable school signs should not be placed within the roadway at any time. In residential districts where pedestrian movement occur or where there are other obstructions to visibility, the clearance between the bottom of the sign to the level of the roadway edge should be $7 \mathrm{ft}$. minimum.

Typical signs to be presented herein are school advance signs, school crossing signs, school bus stop ahead signs, school speed limit signs, and parking and stopping signs.

School advance sign is to be used in advance of locations where school buildings or grounds are adjacent to the highway, or in advance of established school crossings not adjacent to the highway, or in advance of established school crossings not adjacent to a school ground. Dimensions of this sign should be a minimum of $36^{\prime \prime} \times 36^{\prime \prime}$, and installed at a distance greater than $150 \mathrm{ft}$, but less than $700 \mathrm{ft}$. from the pofnts specified above.

School crossing sign is to be used at established crossings including signalized locations used by children going to and from school, unless crossings are controlled by stop signs. This sign should be errected at the crosswalk, or at the most possible minimum distance in advance of the crosswalk. The dimensions of these kind of signs should be kept to $36^{\prime \prime} \times 36^{\prime \prime}$.

School bus stop ahead sign is to be installed at locations where a bus stopping to pick up passengers or release them could not be seen 
for a distance of $500 \mathrm{ft}$. in advance. Minimum size is $30^{\prime \prime} \times 30^{\prime \prime}$.

School speed limit signs are used to specify the speed Iimits in areas where reduced speed zones around schools are established in accordance with law or statute. Dimensional and technical details as weII as types and specifications should be in conformance with those offered and displayed by the MUTCD.

Parking and stopping signs consist of a wide variety of regulations. They are used to govern the stopping and standing of vehicles in school areas. Typical examples of these signs would be as follows:

1. No Parking 8:00 a.m. to 5:00 p.m. School Days Only

2. No Stopping 8:00 a.m. to 5:00 p.m. School Days OnIy

3. 5 min. Loading 8:00 a.m. to 5:00 p.m. SchooI Days OnI. I

Legend on parking signs should specify the regulation applicable, and in addition, they should also conform to standards of shape, color, position and use. In general, the following information is to be displayed from top to bottom of the sign as applicabie:

1. Restriction or prohibition

2. Time of day it is applicable, if not at aII hours

3. Days of week applicable, if not every day $I$

For technical and dimensional details of these signs as weII as specifications, the MUTCD should be closely consulted.

2. Markings - Pavement markings have a function of their own as well as a supplementary role to the regulations or warnings of other devices such as traffic signs. Markings are subject to deterforiation due to snow, rain, and heavy traffic. However, with proper maintenance, they would still have the advantage of conveying warnings or information to 
the motorists without diverting their attention from the roadway.

Crosswalk lines are solid white lines delineating both edges of the crosswalk. They should not be less than 6 inches wide and 6 feet apart. In some special cases, they could be increased to 24 inches in width. Crosswalk lines are of particular value at intersections along an established school route where a conflict exists between vehicular traffic and school children crossing the roadway. Visibility could be enhanced by including a set of white lines marked transversely between the crosswalk lines. These should be approximately 12 " to $24^{\prime \prime}$ wide and spaced apart also $12^{\prime \prime}$ to $24^{\prime \prime}$ with angles of $45^{\circ}$ or $90^{\circ}$ to the crosswalk lines.

Stop lines are also solid white lines, $12^{\prime \prime}$ to $24^{\prime \prime}$ in width and extending across all approach lanes as an indication for vehicles to stop. Ordinarily these lines are placed 4 feet in advance of and parallel to the nearest crosswalk line.

Curb markings for parking restrictions are usualiy intended to be for delineation and visibility purposes. However, suppiemented by the installation of standard signs, they could establish any desirable regulations for parking. In the event such signs are not used, the contemplated regulations should be stenciled on the curb. Though yeilow and white are the usual colors used for curb markings, local authorities may specify special colors as a supplement to standard signs.

Word and symbol markings on pavement may be used for guiding, warning, or regulating traffic. They should be white in color and never exceed three lines of words and/or symbols. When marked for mandatory messages, they may be used in support of standard signs, but never 
alone by themselves. The letters and symbols should be eIongated in. the traffic direction due to the low angle at which they are viewed. by the approaching motorists. The MUTCD should be consulted for further technical and dimensional details.

3. Traffic Signals - Traffic signals are standard traffic controI devices used to regulate traffic. Their installation is highiy desirable at pedestrian crossing intersections in school areas. Justification of signal installation would be established upon satisfying the following warrants:

A. The traffic volumes on the major street and the higher volume minor street approach to the intersection satisfy the minimum limits indicated in the following table.

$\begin{array}{clc}\text { Number of Lanes for Moving } & \text { Vehicles per hour Vehicles per hour on } \\ \text { Traffic on Each Approach } & \begin{array}{l}\text { on Major Street } \\ \text { (total on both }\end{array} & \begin{array}{c}\text { Sigher Volume Minor } \\ \text { Stret Approach }\end{array} \\ \text { Major Street Minor Street } & \text { (approaches) } & \text { (one direction only) }\end{array}$

$\begin{array}{llll}1 & 1 & 500 & 150\end{array}$

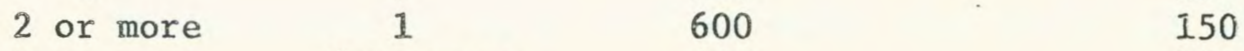

2 or more 2 or more $\quad 600 \quad 200$

12 or more $500 \quad 200$

B. The traffic volumes specified in the following table, ${ }^{1}$ appear on the major street and the higher volume minor street approach to the intersection for each of any 8 hours of an average day, and in addition, the signal installation would not serfousiy interrupt progressive traffic flow.

$1_{\text {MUTCD (3), pg. 236-237 }}$ 
Number of Lanes for Moving Traffic on Each Approach

Major Street Minor Street
Vehicles per hour on Major Street (total on both approaches)
Vehicles per hour on Higher Volume Minor Street Approach (one direction on. Iy)

$\begin{array}{cccr}1 & 1 & 750 & 75 \\ 2 \text { or more } & 1 & 900 & 75 \\ 2 \text { or more } & 2 \text { or more } & 900 & 100 \\ 1 & 2 \text { or more } & 750 & 100\end{array}$

C. The following traffic volume exist for each of any 8 hours of an average day.

i. On a major street, 600 or more vehicles per hour enter the intersection (total of both approaches); or 1,000 or more vehicles per hour (total of both approaches) enter the intersection on the major street where there is a raised median island $4 \mathrm{ft}$. or more in width.

ii. In addition, during the same 8 hours as in part (a), there are 150 or more pedestrians per hour on the highest volume crosswalk crossing the major street. I

D. The delay time between adequate gaps is excessive when children are using crosswalks in school areas.

E. Progressive movement control requires at times traffic signaI installations at intersections where they would not otherwise be warranted. This warrant is satisfied when:

i. On a one way street or a street which has predominately undirectional traffic, the adjacent signals are so far apart they do not provide the necessary degree of vehicle platooning and speed control.

ii. On a two way street, adjacent signals do not provide the necessary degree of platooning and speed control; the proposed and adjacent signals could constitute a progressive signal system. 2

F. The accident experience justifies the signal warrant. This applied when:

${ }^{1}$ MUTCD, (3), pg. 237
${ }^{2}$ MUTCD, (3), pg. 239 
i. Adequate trial of less restrictive remedies with satisfactory observation and enforcement has failed to reduce the accident frequency.

ii. Five or more reported accidents, of types susceptibie of correction by a traffic control signal, have occurred within a 12 month period and each accident involved personal injury or property damage to an apparent extent of $\$ 100$ or more.

iii. There exists a volume of vehicular and pedestrian traffic not less than $80 \%$ of the requirements specified in the minimum vehicular volume warrant, the interruption of continuous traffic warrant, or the minimum pedestrian volume warrant set forth above. 1

G. When concentration and organization of traffic flow networks need be encouraged, traffic signal may be warranted if a common intersection of two or more major routes has a total entering volume of at least 800 vehicles, existing or immediately projected during the peak hour of typical weekday, or each of any five hours of a Saturday and/or Sunday.

H. When no single warrant is justified alone, but two or more warrants are satisfied to $80 \%$ or more of the stated values, an installation of traffic signal may be warranted provided that adequate trial of other remedial measures which cause less delay and inconvenience to traffic, have been investigated before the installation.

Installation of signals under the 4 th warrant should satisfy the following:

1. Pedestrian indications shall be provided at least for each crosswalk established as a school crossing. ${ }^{2}$

$1_{\text {MUTCD, (3), pg. } 239}$

2MUTCD, (3), pg. 335 
2. At an intersection, the signal normally should be traffic actuated. Intersection installations that can be fitted into progressive systems may use pretimed control.

3. At non-intersection crossings, the signal should be pedestrian actuated, parking and other obstructions to view should be prohibited for at least $100 \mathrm{ft}$. in advance of and $20 \mathrm{ft}$. beyond the crosswalk, and the installation should include suitable standard signs and pavement markings. Special police supervision and/or enforcement should be provided for a new nonintersection location.1

Traffic facing a 'circular green' signal may proceed straight through or turn right or left unless there is a sign that prohibits either turn. Vehicles making a turn should yield the right-of-way to other vehicles and pedestrians crossing within the intersection or: an adjacent crosswalk.

Traffic facing 'green arrow' signal, whether alone or combined with another indication may cautiously enter the intersection only to make the movement indicated by such arrow, or such other movement as permitted by other indications shown at the same time. This vehicular traffic should yield the right-of-way to pedestrians and other vehicies lawfully using the intersection.

Pedestrians facing any green signal, unless directed otherwise by a pedestrian signal or the green signal is a turn signal, may proceed across the roadway whether the crosswalks are marked or not.

Vehicular traffic facing a steady 'circular ye11ow' or 'yellow arrow' signal is warned of green termination and red exhibition, so that vehicles can prepare for a stop before entering the intersection. When pedestrians are facing the same signals, they are alerted to the $1_{\text {MUTCD, (3), pg。 } 335}$ 
insufficient time to cross the roadway before a red indication is exhibited.

Vehicular traffic facing a steady 'circuIar red' signaI aIone should stop at marked stop line until an indication to move is exhibited. If there is a sign permitting a turn, vehicles may cautiousiy enter the intersection to make the turn after a stop is secured. Right-of-way should be given to traffic lawfully within the intersection. When pedestrians are facing such a signal, they should not cross the roadway unless otherwise directed by a pedestrian signal.

'Don't walk' indication, being steadily illuminated warns pedestrians not to enter the roadway in the direction of the indication. When the indication is flashing, pedestrians are not to cross the roadway and those who have partly crossed, should seek a sidewalk or a nearby island.

The 'walk' indication when steadily Illuminated permits pedestrians to cross the roadway in the direction of the indication. When flashing, the indication warns for possible conflict between pedestrians and vehicles.

Flashing 'circular yellow' indication, displayed as a speed Iimit sign beacon, warns that the school speed limit shown on the sign is in effect.

Push-button detectors should be designed to operate on a circuit not to exceed 18 volts. They should be located near each end of crosswalks where actuation is required. Permanent-type signs should be mounted above or in unit with the detectors, explaining their purpose and use. At certain locations it may be desirable to supplement this 
sign with a larger sign suspended over the sidewalk to call attention to the push button.

At non-intersection school signal installations, the pedestrian crossing is an exclusive interval. Under all circumstances, pedestrians should have sufficient time to cross the roadway at a signalized intersection. At an intersection there are four basic combinations of pedestrian signal intervals with vehicular signal operation:

1. Combined Pedestrian-Vehicular Interval - a signal phasing wherein pedestrians may proceed to use certain crosswaiks and vehicles are permitted to turn across the said crosswaik. (the pedestrian indication shall be flashing WALK)

2. Exclusive Crosswalk Interval - a single phasing wherein pedestrians may proceed to use certain crosswalks but vehicles are not permitted to move across these crosswalks during the pedestrian movement (the pedestrian indication shaII be steady WALK)

3. Leading Pedestrian Interval - a single phasing wherein an exclusive pedestrian interval, in advance of the vehicular interval, is provided for pedestrians (the pedestrian indication sha11 be steady WALK). When the leading pedestrian intervaI. is terminated, and a combined pedestrian-vehicular intervaJ. begins, the WALK indication may begin to flash, and

4. A11 Pedestrian Phase - a single phasing wherein pedestrians may proceed to cross the intersection in any direction during an exclusive phase while all vehicles are stopped (the pedestrian indication sha11 be steady WALK). 1

Coordination between operating signals should be provided including both pretimed and actuated signals within the appropriate distances. Once again, for design technicalities and more specific details reference should be made to the MUTCD.

Crossing Supervision: School crossing supervision comprises of two types; ${ }^{2}$ one is adult control of pedestrians and vehicles with adult

$1_{\text {MUTCD }}$ (3), pg. 339

${ }^{2}$ MUTCD, (3), pg. 346 
guards or police officers, and the other would be student control of only pedestrians with student patrol.

Adult guards are used to provide gaps in traffic at school crossings based on an engineering study indicating a need for adequate gaps to be created. They should be special police officers assigned by the local police agency with the latter being responsible for their selection, training and supervision. Selection of adult guards should be made in accordance with high standards. Adults should understand children and have the following qualifications:

1. Average intelligence

2. Good physical conditions including sight and hearing

3. Mental alertness

4. Neat appearance

5. Good character

6. Dependable

7. Sense of responsibility for childrens' safety ${ }^{1}$

Adult guards should wear a uniform that differs from that used by police officers so that they could be recognized by all motorists as well as pedestrians. Adult guards ' responsibility is limited to helping children by creating safe gaps for crossing a roadway. They are by no means a replacement for police duties.

Supervision of school crossing is the responsibility of police officers only in emergency situations. When there is no need to create adequate gaps in traffic, student patrols may be used to direct and control children at crossings near schools. Their selection should be made carefully from the 5 th grade or higher on the basis of leadership and reliability qualities for patrol membership. School authorities should 
be responsible for organizing, instructing, and supervising student: patrols with the assistance of the local police.

Grade Separated Crossings: Grade separation consists of constructing either overpass or underpass structures to separate vehicular: traffic from pedestrian flow. Overpass grade separation seems to be preferred over the underpass for maintenance and supervision purposes. Grade separated crossings may be considered only when the physical characteristics of the location make such a structure feasibie. For. design policies and guidelines, the American Association of State Highway officials should be consulted.

\section{State Programs}

There have been several measures applied to increase the effectiveness of school crossing protection. While most innovative methods have originated with local agencies, and will be discussed in the next section, some illustrations of such methods proposed or examined at the state level have been included.

The first measure discussed is the "use of red flashing beacons during peak periods at school crossings" having large pedestrian flow rates. This measure developed by the North Dakota Highway Department, is under consideration ${ }^{1}$ by a national committee responsible for the development of the UMTCD. In Kentucky the Bureau of Highways examined the effectiveness of school signs with flashing beacons ${ }^{2}$ installed in accord with the UMTCD. While the speed limit signs indicated $20 \mathrm{mph}$

United States Department of Transportation (4), pgs. 55-56

${ }^{2}$ Zegeer, C. V., 
the spot speed survey revealed a disappointing $36 \mathrm{mph}$. In addition, the speed uniformity was reduced, thereby, increasing internal energy losses and the accident propensity.

On September 22, 1955, the New Mexico State Highway Commission adopted a "School Crossing Manual" for use and application in the State of New Mexico. This Manual became void in 1973 and a new edition was adopted. The Manual itself, with the exception of a few minor differences in procedural policies, does not really present any additional. concepts beyond what has already been pointed out by the MUTCD or the ITE Program. The New Mexico Program seems to be typical of what has been developed by other states. The traffic control regulations set forth by the New Mexico State Highway Department are cIoseIy related to the State's Motor Vehicle Laws. When called upon, with regard to school crossing investigations, through a formal written request by the Superintendent of Schools or School Board, the New Mexico State Highway Department will normally pursue the following considerations:

1. An accident summary

2. Photographs showing approaches and any sight restrictions

3. Speed studies to determine the 85 percentile speed with and without school crossings taking place.

4. Counts consisting of children and vehicles per hour during the time of school take-up and dismissal.

5. A topographical map to show geometry and general layout of the proposed school crossing area.1

${ }^{1}$ State of New Mexico (6), pg. 2 
6. Following the completion of the investigations the results shall be reviewed by a Traffic Services Engineer who will. select the proper traffic control device based on the warrants.

7. Upon completion of the installation an after study wijJ be directed by the Traffic Services Engineer to assure adequate control, compliance by the motorists to the reduced speed zone, and reasonable and safe usage of the school crossing by the school children.1

In their school crossing manual, the State Highway Department calls for removal of all portable school crossing signs by state forces in accordance with the New Mexico motor vehicle laws. School crossings should then be investigated for determining the appropriate traffic control devices to be installed. All school crossings under the jurisdiction of the State of New Mexico are to be reviewed and inspected when the majority of children are crossing, unless determination of hazard is to be made based on accident history, sight restrictions or ground topography. The selection of the proper traffic control devices along with their specifications is made in accordance with the New Mexico Manual for Uniform Traffic Control Devices which is, for aIJ practical purposes, the same as the national MUTCD, a presentation of which was made earlier in this document.

Chapter 10 of the California State Traffic Manual ${ }^{2}$ sets forth the basic laws and regulations concerning the protection of school children, together with the responsibilities of people and organizations in promoting school safety. It further establishes fundamental principIes and prescribes standards to be used in school zones on all streets and highways in the State of California.

$1_{\text {State of New Mexico (6), pg. } 2}$

${ }^{2}$ State of California (7), pg. 10-1 


\section{Local Programs}

Numerous programs as well as research projects and studjes have been prepared by local governmental agencies concerning the protection of school children. However, in an attempt to avoid any dupifcation, only few representative samples are selected. These samples wiII be treated under two categories. First, city programs which deaI primarily with school crossing protection and warrants for the installation of traffic contro1 devices, and second, research and studies which are initiated to evaluate the effectiveness of traffic control measures.

City Programs: City programs include warrants for the installation of traffic control devices in the cities of the State of CaIffornia as proposed by the California Traffic Control Devices Committee. I They also include new ideas promoted by the City of Los Angeles as weII as the City of Seattle.

As a result of section 21272 of the California Vehicle Code, a legislation enacted in $1968,{ }^{1}$ proposed warrants for the installation of traffic control devices in school zones, were prepared and recommended. by the "California Traffic Control Devices Committee", and distributed to the appropriate authorities in the cities of the State of CaIifornia for review and consideration. Under the said legislation, the city, upon request from the governing body of the school district, will within 90 days, undertake a traffic survey for locations in question, and if protection is found to be warranted, the appropriate protective devices should be installed by the city with the cost being equally born 
by the school district. In their document, the California Traffic Control Devices Committee has established a practical criteria for warrants on traffic control measures; however, rather than conveying the whole package here, only the new additional innovations wiII be considered to avert any possible repetition of items already pointed. out.

Signs used in school zones should be of permanent type and in conformance with the design specifications of the Department of Public Works, State of California, as published in the State of CaIifornia Division of Highways Planning Manual, Part 8-Traffic. ${ }^{1}$ Nonuniform. signs are prohibited and hence should not be installed. Portable signs are not allowed within the roadway at any time. Whenever a divided highway has a center median of ample width, signs should be located in the median as well as on the right of the roadway.

When it becomes necessary to extend or create adequate gaps in the flow of traffic to permit pedestrian crossing opportunities and no other controlled crossing is available within 600 feet, signals should be installed when the following warrants are met: ${ }^{1}$

1. Urban conditions - 500 vehicles and 100 school-age pedestrians for each of any two hours daily while children are crossing to or from school; or 500 vehicles per hour for each of any two hours while children are crossing to or from school, and a minimum total of 500 school-age pedestrians during the entire day.

${ }^{1}$ California Traffic Control Devices Committee (8) 
2. Rural conditions - 350 vehicles and 70 school-age pedestrfans per hour during each of any two hours daily while children are going to and from school; or 350 vehicles per hour for each of any two hours while children are crossing to or from school and a minimum total of 350 school-age pedestrians during the entire day.

When critical approach speed exceeds $40 \mathrm{mph}$ or approach visibility is less than the required safe stopping sight distance for prevaiIing critical speed, rural warrants should be applied.

Adult crossing guards should normally be assigned where official supervision of elementary school children is desirable while they cross a public street or highway, and at least 40 elementary school-age pedestrians per hour for each of two hours utilize the crossing on the way to or from school. Whenever the critical approach speed exceeds 40 $\mathrm{mph}$, the warrants for rural conditions should be applied. AduIt crossing guard protection will be warranted under the following conditions: ${ }^{1}$

A. Uncontrolled Crossings on the Suggested Safest Route to SchooI

1. Where there is no controlled intersection within 600 feet of the location where a request for an adult crossing guard is made.

2. Under urban conditions where the vehicular traffic volume exceeds 350 during each of any two hours during which 40 or more school children normally cross while traveling to or from school. Under rural conditions, the same criteria 
applies, except that the vehicular traffic volume exceeds 300 and the school children is equal to or more than 30 .

\section{B. Stop Sign Controlled Crossings}

Where the vehicular traffic volume on undivided roadways of four or more lanes exceeds 500 per hour during any period when the children are normally going to or from school.

C. Signa1-Controlled Crossings

1. Where the number of vehicular turning movements through the crosswalk where children must cross exceeds 300 per hour while children are going to or from school.

2. Where there are extenuating circumstances not normaliy experienced at a signalized intersection such as crosswalks more than 80 feet long with no median refuge area, or an abnormally high percentage of commercial vehicles with operating characteristics substantially different from those of the passenger vehicle.

Pedestrian safety problems are not Ifmited to crossing locations, since significant hazards also prevail where physical conditions require children to walk in or adjacent to the roadway in rural or suburban areas where the speed and volume of traffic, sight distance and roadway width leave little margin for human error. Construction of a pedestrian walkway at least four and a half feet wide and physically separated by berm, rail, fence, etc. from the vehicular roadway may be justified when the following conditions are fulfilled. ${ }^{1}$ 
1. The roadway lies on the suggested softest route to school.

2. Road shoulders are less than 6 feet wide.

3. More than 20 school children use the route while waIking to and from school and vehicular traffic exceed 100 cars per hour.

4. The school district has officially requested pedestrian walkway improvements.

Where the pedestrians walk on the shoulder of the roadway, adequate shoulders of six feet or more in width should be avaflabie along both sides so that pedestrians may always walk facing oncoming traffic. Where separate walkway is provided, facilities may be Iimited to one side of the roadway.

The STEPS project carried out by the City of Los Angeies on July 1, 1971 has revealed the necessity of including other languages on school route maps, such as Spanish, Chinese and Armenian, so that nonEnglish speaking pedestrians can be convenienced. ${ }^{I}$ As this may apply well to such a city as Los Angeles where a large number of Spanishspeaking community reside, it may not be as significant in other areas where English is the only dominant language.

In 1973, the City of Seattle, Department of Engineering, established a unique criterion for the assignment of adult guards at hazardous intersections. Under this criterion, intersections suggested for aduIt guard control, should be studied using the prioritizing system below and then arranged by point rank. All locations with point values greater ${ }^{1}$ City of Los Angeles, (9), pgs. $18 \& 20$ 


\section{Study Factors 1}

\section{Factor}

1. Adequate gaps in traffic stream

2. Turning volume

3. Volume of children

4. Investigator's judgment

5. Sight distance

6. Pedestrian signal indications

7. $85 \%$ vehicular speed

8. Signal phases

9. Signal cycle length

10. Street classification

\section{Point Range}

0 to 24

a to no Ifmit

0 to 10

0 to 8

0 to 7

0 to 6

0 to 5

0 to 4

0 to 3

0 to 2

than 13 should be considered as warranted. The study procedure requires a qualified investigator to be placed at each location under consideration. The investigator will count or otherwise measure the actual quantities of each of the above listed factors, except the judgment factor. He will also list the non-quantifiable characteristics observed or known to exist. Items of field collected data will be applied to the point valuation graphs of Figure 2, with the total points summarized. The locations studied will be finally arranged chronologically in terms of the total points.

Research and Studies: Research and studies have been conducted by several local agencies for examining the effectiveness of some traffic control measures. These agencies include the City of Seattle, City of Los Angeles, City of Portland, City of San Diego, City of Arvado, and the City of San Jose.

The Traffic and Transportation Division of the Seattle Engineering

${ }^{1}$ City of Seattle (10); pg. 2 


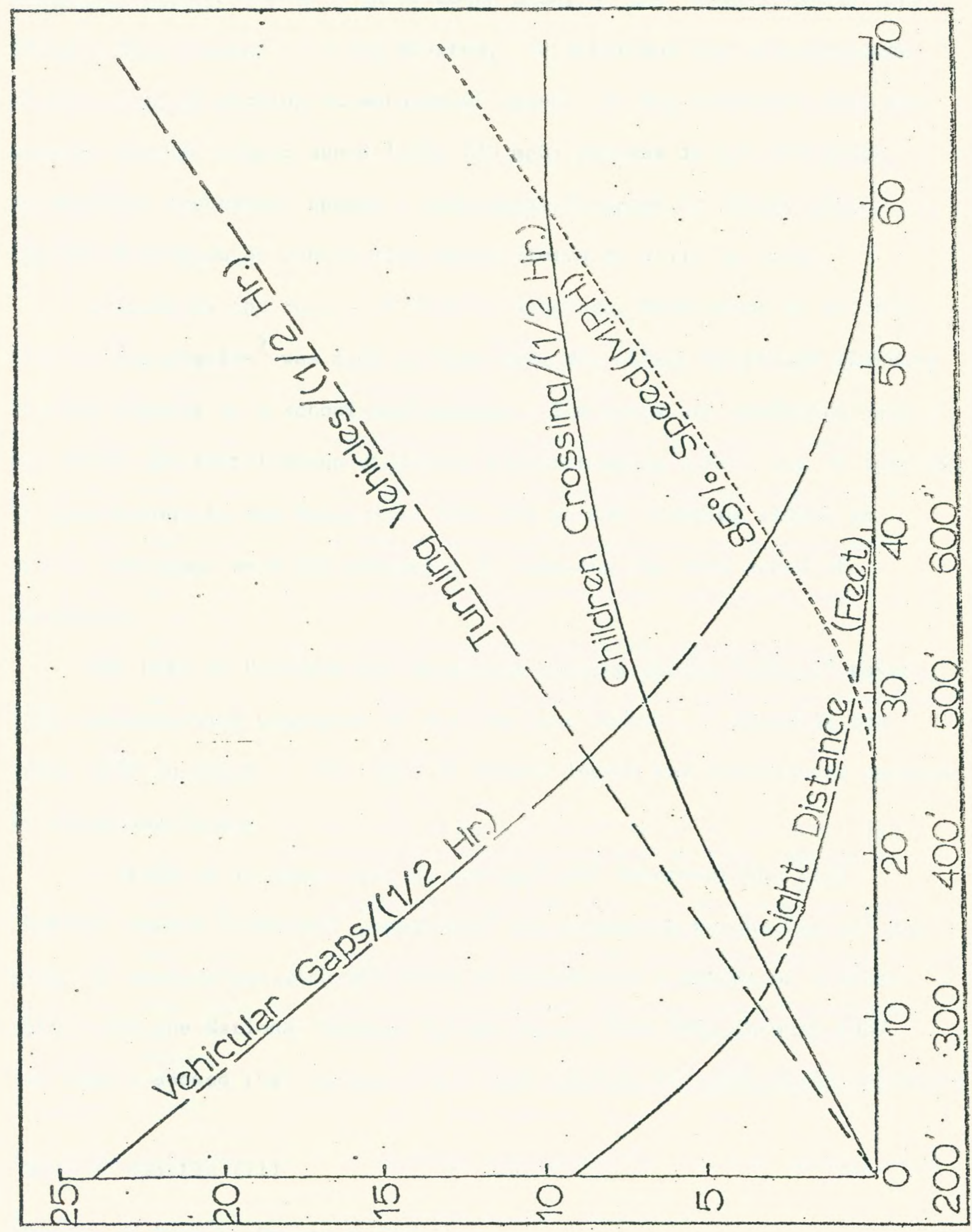

\section{POINTS}

Figure 2. Adult guard priority point as signment $\operatorname{graph}^{1}$ 
Department has conducted a three-month study of the "school, speed limit $20 \mathrm{mph}$, when flagged" signing program, ${ }^{1}$ to determine the effectiveness of this type of signing on motorists ${ }^{8}$ speed. It was concluded that the present reduced school speed limit (20 $\mathrm{mph}$ ) program is not effective in reducing motorists ${ }^{p}$ speeds. Additional research to investigate the effectiveness of school zone speed limits is stili in order.

A study by the Bureau of Traffic Research, Department of Traffic, City of Los Angeles ${ }^{2}$ was made to determine the effect of yellow flashing traffic signals in a school environment. The study was conducted before and after the installation of yellow flashers while school was in session. In conclusion, it was determined that the yellow flashing lights at school crossings were not effective in reducing the mean speed of: motorists.

The City of Portland has installed special raised "school" pavement legends which consisted of traffic lane markers 4" diameter and about $1 / 2^{\prime \prime}$ in height. This type of school legend has experienced success in enhancing safety. ${ }^{3}$

A study of accident rate at unsignalized intersections with "marked" versus "unmarked" crosswalks" was conducted by the City of San Diego in cooperation with the State of California's Office of Traffic Safety and the National Highway Safety Bureau from 1963 through 1967. The result showed that during this 5-year period, 177 pedestrian accidents

\section{${ }^{1}$ City of Seattle (11)}

${ }^{2}$ Bureau of Traffic Research (12)

${ }^{3}$ Martini, Mario J. (13)

${ }^{4}$ Herms, Bruce F。 (14) 
occurred in marked crosswalks while 31 in comparable unmarked crosswalks yielding a ratio of approximately 6 to $1 !^{1}$ Evidence reveaIed that this poor accident record was not due to the crosswaIk being marked as much as it was a reflection on the pedestrians' attitude and behavior when using the marked crosswalk. In general, marked crosswalks have the following advantages and disadvantages:

\section{Advantages -}

1. May help pedestrians orient themselves and find thejr way across complex intersections.

2. May help show pedestrians the shortest route across traffic.

3. May help show pedestrians the route with the Ieast exposure to vehicular traffic and traffic conflicts.

4. May help position pedestrians where they can be seen best by oncoming traffic.

5. May help utilize the presence of luminaires to improve pedestrian nighttime safety.

6. May help channelize and limit pedestrian traffic to specific locations.

7. May aid in enforcing pedestrian crossing regulations.

8. May act, in a limited manner, as a warning device and reminder to motorists that this is a location where pedestrian conflicts can be expected.

\section{Disadvantages -}

1. May cause pedestrians to have a false sense of security and to place themselves in a hazardous position with respect to vehicular traffic.

2. May cause the pedestrian to think that the motorist can and will stop in all cases, even when it is impossible to do so.

3. May cause a greater number of rear-end and associated coilisions due to pedestrians not waiting for gaps in traffic.

4. May cause an increase in fatal and "serious injury" accidents.

5. May cause an increase in community-wide accident insurance rates.

6. May cause a disrespect for all pedestrian regulations and traffic controls. 2

The following is some accident statistics for the 400 unsignalized

$1_{\text {Herms, Bruce F. (14), pg. } 30}$ 
intersections studied by the City of San Diego: ${ }^{I}$

\begin{tabular}{|c|c|c|c|}
\hline & Marked & Unmarked & Ratio \\
\hline Total accidents & 177 & 31 & $5.7 / 1$ \\
\hline Pedestrian volume & 2.9 & 1.0 & $29 / 1$ \\
\hline Vehicular volume & 1.0 & 1.0 & $I / I$ \\
\hline
\end{tabular}

The City of Arvada, Colorado, has promoted the use of varfabie message signs (82 Varicom Cycle Control Devices) along the safe school routes in an attempt to reduce the vehicular speed during the period the children are coming and going. ${ }^{2}$ When the motorized panels of the variable message signs are opened they all read the word "schooI". This appears in black on a yellow background above a conventional black on white "Speed Limit 20". At times when children are not traveling, the signs are closed to display a variety of pictorial and printed. messages all in accordance with the MUTCD. All indications so far have verified the effectiveness of these signs as weII as the pubIf:c satisfaction.

Few changes and/or modifications in the MUTCD have been requested by local agencies in an effort to update or improve the current standards. Examples of these requests are pointed out herein. below:

Elkhart County, Indiana, asked approval of a pentagon shaped school bus symbol sign with an educational plaque reading either, Watch for School Bus or School Bus Turnaround. According to the Submitting organization, the proposed school bus symbol sign was intended to replace the School Bus Stop Ahead signs S3-1 in Section 7B-11 of the MUTCD. As implied in the request, the proposed symbol sign would be accepted through-

${ }^{1}$ Herms, Bruce F。(14), pgs. 15-17

${ }^{2}$ Grady, James 0.(15), pg. 39 
out the states as an improvement of the existing word message sign. S3-1. The request was denied because a new national standard symbol design for sign $53-1$ was in the process of being developed.

The City of Seattle, Washington, requested adoption of the schoolpedestrian signal design concept which utilizes stop signs to control vehicular movement on the minor approaches and signals to control. vehicular movement on the major approaches at pedestrian crossing intersections. The request was denied pending a research study related to pedestrian improvements, currently under way by the FederaI Highway Administration, Office of Research, and development of recommended standards for alternative specialized pedestrian control techniques.

In San Jose, California, several configurations of traffic buttons were examined ${ }^{1}$ to determine the speed reduction effectiveness of such. a practice. The notion in this control measure was probing for a device which would result in better conformance, on the part of motorists, with special speed limits such as school zones. There were several interesting findings obtained from the San Jose work; nameIy, (I) the speed bumps did not reduce vehicle speeds, (2) speed bumps result in a hazard to motorcycles and bicycles, and (3) noise poilution can be expected from the use of such devices.

\section{Miscellaneous Programs}

Other school safety programs include an appreciable number of articles, publications, and manuals published by private organizations as well as individuals. Examples of such programs are represented by ${ }^{1}$ Allen, C.D. and L. B. Walsh (16), pgs 11-14 
a research paper prepared for the Federal Highway Administration and school crossing manual published by the Cedar Raplds SchooI Crossing Safety Committee, Cedar Rapids, Iowa.

A research paper prepared for the Federal Highway Administration. under the title "School Trip Safety and Urban Play Areas", I revealed that a tremendous number of school trip-related pedestrian accidents were due to lack of understanding of traffic controls by the students as well as the drivers. This conclusion was based on a survey designed. to evaluate the knowledge and perception of traffic control devices by young pedestrians on one hand, and drivers on the other hand. Another study on the subject, performed in Sweden, suggested that the average child does not obtain the requisite degree of maturity as a pedestrian. until between nine and twelve years of age. It was indicated that:

1. Children's diminutive stature makes it difficult to size up a traffic situation.

2. Children are incapable of distributing their attention (they concentrate on one thing at a time--often play--or take a vague overall impression).

3. They have difficulty discriminating direction of sound.

4. They cannot distinguish between right and left.

5. Many believe the safest way to cross a street is to run. ${ }^{2}$

Thus full understanding of traffic control devices on the part of children is quite imperative, and without the cooperation between parents, teachers, and other responsible organizations in achieving this objective, safety will not be possible.

The school crossing manual put out in 1974 by the Cedar Rapids ${ }^{1}$ Reiss, Martin L. and H. Douglas Robertson (17), pg. 135
${ }^{2}$ Reiss, Martin L. and H. Douglas Robertson (17), pg. 136 
School Crossing Safety Committee, Cedar Rapids, Iowa, gives an insight into additional warrants for traffic control devices. These warrants are based on policies and practices which have been proven effective in the solution of community school pedestrian problems. A summary of the minimum warrants as set forth in this manual is outined herein beIow:

Side Walks: Unit points are assigned as applicable in accordance with the following tables. ${ }^{1}$ A total unit points greater than 75 wouId warrant a sidewalk construction on one side of the street. If the accumulative total points exceed 100, the sidewalk installation would then be warranted on both sides of the street. This process invoIves six conditions:

1. Vehicular volume in both directions parallel to the street, during 1 hour period, at which the pedestrian traffic is at maximum.

\begin{tabular}{|c|c|c|c|}
\hline Vehicular Volume & Unit Points & Vehicular Volume & Unit Points \\
\hline $1-49$ & 10 & $150-499$ & 30 \\
\hline $50-149$ & 20 & $500-999$ & 40 \\
\hline & & $1000 t$ & 50 \\
\hline
\end{tabular}

2. Hourly volume of pedestrian traffic in both directions and on both sides of the street.

Pedestrian Volume Unit Points Pedestrian Volume Unit Points

$\begin{array}{cccc}1-24 & 5 & 100-149 & 35 \\ 25-49 & 10 & 150+ & 50 \\ 50-99 & 20 & & \end{array}$

${ }^{1}$ Cedar Rapids School Crossing Safety Committee (18), pg • 20-21 
3. Percentage of trucks in 1 hour period.

Truck-Percentage

$1-4 \%$

$5-9 \%$

$10+\%$
Unit Points

5

10

15

4. The 85 th percentile speed of vehicles.

Speed (MPH) Unit Points Speed (MPH) Unit Points

$\begin{array}{cccc}0-24 & 0 & 35-44 & 20 \\ 25-34 & 10 & 45+ & 30\end{array}$

5. Usable walkway - the distance between the edge of the street and the property line.

Usable Walkway (ft) Unit Points Usable WaIkway (ft) Unit Points $\begin{array}{lll}1-5 & 40 & 11-15\end{array}$

$\begin{array}{llll}6-10 & 15 & 16+ & 0\end{array}$

6. Special conditions.

Conditions

Commercial or industrial area

Available sight distance

Other special conditions
Unit Points

$0-10$

$0-10$

$0-10$

Stop Signs: A stop sign is usually inconvenient to the motorist and hence should be used only where warranted. At an intersection it may be warranted if one or more of the following conditions exist.

1. Intersection of a main road with less important road where hazard may exist with normal right-of-way application.

2. Street entering a through highway or street.

3. Unsignalized intersection in signalized area. 
4. Intersections involving a combination of high speed, restricted sight and serious accident record.

A multi-way stop sign may be used at locatfons where intersecting roads experience approximately an equal volume of vehicular traffic. They are warranted under any of the following conditions:

1. Five or more accidents in one year which could be avoided by such sign installation.

2. 500 vehicles or more per hour per 8 hours of an average day, approaching an intersection from all directions. In addition, the combined vehicular and pedestrian volume from the minor street or highway averages at least 200 units per hour for the same 8 hours, with an average delay to minor street vehicular traffic of at least 30 seconds per vehicle during the maximum hour.

3. Minimum vehicular volume of 70 percent of the above requirements, when the 85 percentile approach speed of the major. street traffic exceeds $40 \mathrm{mph}$.

School Crossing Signalization: Warrants for marking or signalizing a crosswalk are based on a point system evaluation of gap time, pedestrian volume, vehicle approach speed, and general conditions at the crossing location. Marking is warranted at a location rating a total of 10 points or more, with at least one point being related to pedestrian volume warrant. The minimum warrant for the installation of a signalized crossing is met when a location rates a total point evaluation greater than 16 points, two of which being based on the gap time warrant. The installation of a flasher in advance of a signalized crossing is 
warranted when the location rates a total point evaluation greater than 20 points.

The gap time warrant is established on the basis of the number. of gaps equal or exceeding the required pedestrian crossing time in an average 5 minute period during the peak vehicle hour. The required pedestrian crossing time includes a 3 second reaction time plus the time to cross the street at a walk rate of 3.5 feet per second. Mathematically, the number of gaps per 5 minute period ${ }^{1}=$

$\frac{\text { Usable gap time in seconds accumulated during } I \text { hour period }}{12 \times \text { pedestrian crossing time }}$ Where, pedestrian crossing time $=$

$$
\frac{\text { Curb-to-Curb Width }}{3.5 \text { Feet Per Second }}+3 \text { seconds }
$$

Point assignment used in determining the gap time warrant should conform to the following: ${ }^{2}$

$\begin{array}{cc}\begin{array}{l}\text { Average number of gaps } \\ \text { per } 5 \text { Minute Period }\end{array} & \begin{array}{l}\text { Maximum Number of } \\ \text { Points Allowed }\end{array} \\ 0-0.99 & 10 \\ 1-1.99 & 8 \\ 2-2.99 & 6 \\ 3-3.99 & 4 \\ 4-4.99 & 2 \\ 5 \text { or over } & 0\end{array}$

The pedestrian volume warrant is based on the total number of pedestrians crossing in the vicinity of the location under consideration, during the peak vehicle hour. In case the location is an intersection,

${ }^{1}$ Cedar Rapids School Crossing Safety Committee (18), pg. 41

${ }^{2}$ Cedar Rapids School Crossing Safety Committee (18), pg. 42 
the volume would reflect the number of pedestrians in both crosswalks. Point assignment related to this warrant is as follows: I

$\begin{array}{cc}\begin{array}{c}\text { Total Nuber of Pedestrians } \\ \text { in } 1 \text { hour }\end{array} & \begin{array}{c}\text { Maximum Number of } \\ \text { Points Allowed }\end{array} \\ \begin{array}{c}11-10 \\ 1-30\end{array} & \begin{array}{c}\text { A } \\ 31-60\end{array} \\ 61-90 & 6 \\ 91 \text { or over } & 8 \\ \end{array}$

The approach speed warrant is based on approach speed from both directions of travel as determined by the investigating engineer through speed study techniques. Point assignment for this warrant is as follows: ${ }^{2}$

\begin{tabular}{lc} 
Approach Speed & $\begin{array}{c}\text { Maximum Number of } \\
\text { Points Allowed }\end{array}$ \\
\hline $20 \mathrm{mph}$ or under & 0 \\
20 or $25 \mathrm{mph}$ & 3 \\
30 or $35 \mathrm{mph}$ & 5 \\
40 or $45 \mathrm{mph}$ & 3 \\
50 or $55 \mathrm{mph}$ & 1 \\
$60 \mathrm{mph}$ or over & 0
\end{tabular}

The general conditions warrant is based on factors affecting the movement of pedestrian txaffic other than those stated above. Consideration is usually given to the intersection location and layout, pedestrian accident history, vehicle turning movement, adjacent grounds

${ }^{1}$ Cedar Rapids School Crossing Safety Committee (18), pg. 42

${ }^{2}$ Cedar Rapids School Crossing Safety Committee (18), pg. 43 
and buildings, and pedestrian generators. Point assignment used for this warrant is limited to one point for each of the following conditions $^{1}$, with a maximum of 5 points for the whole warrant:

1. Major arterial or expressway location

2. Intersection location

3. Skewed crosswalks

4. Pedestrian accident history

5. Adjacent pedestrian generators

6. Sight distance

Adult School Crossing Guards: A warrant for using aduIt school crossing guards is justified when a minimum volume factor of 1600 exists. This factor is determined by adding the following individual volume conditions.

1. The hourly volume of traffic crossing the crosswalk during school crossing periods. If the 85 percentile speed of traffic exceeds $30 \mathrm{mph}, 120 \%$ of the hourly volume should be used.

2. Four times the number of trucks crossing the crosswalk per hour during school crossing periods.

3. Four times the number of turning vehicles crossing the crosswalk per hour during school crossing periods.

4. The hourly volumes of school children crossing in the crosswalk during school crossing periods.

5. A weighted value demonstrating the degree of other hazards affecting a crossing of from 10 (good) to 100 (poor) per each of the following four conditions:

${ }^{1}$ Cedar Rapids School Crossing Safety Committee (18), pg. 43 
a) Number of accidents within 300 feet of crosswalk, with points assigned as follows: $:^{1}$

$\begin{array}{cc}\text { No. of Accidents } & \text { Points } \\ 0-5 & 0 \\ 6-15 & 30 \\ 16-25 & 60 \\ 26+ & 100\end{array}$

b) Traffic congestion as a measure of traffic flow, with points assigned as follows: 1

Level of Service

A (free flow)

B (stable flow-few restrictions)

C (Stable flow)

D (Approaching unstable)

E (Unstable flow)

F (Forced flow)
Points

0
0
25
50
75
100

c) Sight distance of vehicular traffic to the crosswaik, with points assigned as follows: ${ }^{1}$

$$
\begin{aligned}
& \% \text { of Required Sight } \\
& \text { Distance Available }
\end{aligned}
$$$$
140 \%+
$$$$
121-140 \%
$$$$
101-120 \%
$$$$
76-100 \%
$$$$
75 \% \text { or less }
$$

\section{Points}

0

25

50

75

100

${ }^{1}$ Cedar Rapids School Crossing Safety Committee (18), pg. 53 
d) Special conditions with points assigned as follows:

\begin{tabular}{lc}
\multicolumn{1}{c}{ Condition } & Points \\
Offset intersection & 25 \\
Commercial or industrial areas & 25 \\
Street grade exceeding 4\% & 25 \\
Other hazardous conditions & 25
\end{tabular}

In summary, this chapter introduces typical school crossing programs together with additional ideas published on Federal Ievel, State, Local and others. The Federal program outlined in the national MUTCD provides uniform standard devices to be used for regulating traffic. In addition, it provides the necessary criteria for warranting the installation of such devices. The state programs prepared by the individual states explore additional measures, the application of which enhance the effectiveness of school crossing protection. Local programs initiated by local governmental agencies expand to include the innovative concepts not covered elsewhere in the other programs. They are presented in two groups, city programs expIoring supplementary warrants for installing traffic control devices, and research and studies which are conducted independently to evaluate the effectiveness of traffic control measures. Finally miscellaneous programs published by private agencies and school districts close this chapter with further ideas and comments on the subject matter.

${ }^{1}$ Cedar Rapids School Crossing Safety Committee (18), pg. 54 
CHAPTER IV

INADEQUACIES IN THE ITE PROGRAM

This study so far has treated the ITE school crossing protection. program together with the practices of several agencies throughout the nation. It is the intent of this chapter to explore deficiencies in the ITE program by conducting a comparative analysis with the other programs. Inadequacies in the ITE program will be disclosed under three categories, items treated inadequately, items not treated, and ineffective practices currently in use.

\section{Items Treated Inadequately in the ITE Program}

Items treated inadequately in the ITE program are pointed out under public understanding of traffic control devices, school route map, definition of terms, hazardous signalized locations, traffic control devices, and priority system.

Public Understanding of Traffic Control Devices: One of the most important factors which contributes to school crossing safety is the public understanding, particularly by children, of traffic control measures as well as regulations. A substantial number of school trip pedestrian accidents have occurred due to lack of understanding of the measures and regulations by students and drivers. This fact has been verified by the research paper released by the Federal Highway Administration and pointed out in Chapter III under "Miscellaneous Programs". While this fact is stated with emphasis in the introduction of almost a11 other programs, the ITE program makes no mention about it except 
in connection with the school route plan encountered Iater in its recommended practice. It would be well for the ITE program to give more direct attention to the issue of communication with the children, their parents and motorists.

School Route Map: The ITE program suggests using the reverse side of the school route map for instructions on its use and traffic safety. With children being expected to comprehend the plan, such instructions may be more convenient if they would be included on the front side of the map rather than the reverse side. The STEPS project completed by the City of Los Angeles in July 1971 and discussed in Chapter III under "Local Programs" recommends including other languages on school route maps for the convenience of non-EngIish. speaking pedestrians. The ITE program fails to include such a recommendation.

Definition of Terms: Terminology such as adequate gaps and blockades needs to be defined for the reader's convenience in understanding the ITE program. The definition of the adequate gap is not introduced until Appendix A, and without a technical background the reader will be ignorant of the term until he reads said appendix.

Hazardous Signalized Locations: In Step 3 of the ITE program, the study of hazardous school crossings does not include signalized locations. For analysis of such locations, Appendix B at the end of the program's pamphlet is to be consulted. Since signalized crossings are important, as are the non-signalized ones, it seems that an incorporation of the above mentioned appendix into the context of Step 3 in the program would be considerably more appropriate. 
Traffic Control Devices: In general, the ITE program provides an outline of procedures for the logical selection of those locations where school crossings are hazardous. However, it does not offer any criteria or guidelines for determining the traffic control device or measure which will best handle a particular situation. This determination is left for the traffic engineer's judgment which is undoubtediy quite valuable. But without a definite set of warrants for specific measures, consistency of judgment by traffic engineers would not be possible, thus defeating the purpose of uniformity in the protection system.

Priority System: The ITE program contains no priority system in dealing with hazards. Instead, it assigns this responsibility to the School Traffic Safety Committee identified in Step $I$ of the program. In Step 4, the program provides a procedure only to determine whether traffic control at a particular location is needed or not. No mention as such is made as to what type of control should be considered nor how to determine which locations should receive attention first.

\section{Items Not Treated in the ITE Program}

Items not treated in the ITE program include portable school signs, funding, warrants, raised legends, and variable message signs.

Portable School Signs: Use of portable school signs within the roadway is forbidden by the MUTCD as well as the state, local, and other programs reviewed for this document. This prohibition is not included in the ITE program.

Funding: The ITE program does not specify the source of funds to be utilized in financing the installation of the appropriate traffic control devices. This source is identified in other programs such as 
those prepared by New Mexico State Highway Department and California Traffic Control Devices Committee.

Warrants: Although warrants for the installation of traffic control devices are clearly established by local and other programs, the ITE program provides none. The City of Seattle offers unigue criteria for warranting the use of adult guards at hazardous intersections. Warrants for constructing walkways as well as other traffic control measures are set forth in the recommendations proposed by the "California Traffic Control Devices Committee" and "Cedar Rapids School. Crossing Safety Committee", a summary of which has been presented in Chapter II under "Iocal" and "miscellaneous" programs respectively.

Raised Legends: Raised "school" pavement legend with lane markers is being utilized by the City of Portland in Oregon. Consideration of: this measure could be a valuable asset in the ITE program where rain may obscure painted legends.

Variable Message Signs: The use of "variable message signs" aIong the safe school route to reduce the vehicular speed during crossing, has been proven to be effective by the City of Arvada in Colorado. An incorporation of this traffic control device in the ITE program could also be of some value.

Ineffective Practices Currently in Use

Ineffective practices which have been used include the installation of speed limit signs with flashing beacons, speed limit signs with flags, marked crosswalks, and speed bumps.

Speed Limit Signs with Flashing Beacons: The Bureau of Highways 
in Kentucky disclosed that school speed Iimft signs with flashing beacons installed in accordance with the MUTCD, are ineffective in reducing the vehicular speed.

Speed Limit Signs with Flags: A study of the "schooI speed Iimit $20 \mathrm{mph}$, when flagged" signing, conducted by the Traffic and Transportation Division of the Seattle Engineering Department, concluded that flagging the standard school speed limit (20 mph) signing is not effective in reducing motorists' speeds.

Marked Crosswalks: Marked crosswalks at unsignalized fntersections have been reported to yield a higher rate of accidents than unmarked crosswalks. This was one of the findings at a study conducted by the City of San Diego in California between 1963 and 1967.

Speed Bumps: Several types of traffic buttons were experimented by San Jose, California, to determine their effect on speed reduction of vehicles in school zones. The test proved such a practice to be not only ineffective, but also detrimental to both motorcycles and bicycles.

The above was an analysis performed to compare the avaflable nationwide school crossing protection programs against that of the Institute of Transportation Engineers. This included items treated inadequately in the ITE program as well as other items not treated. The anaIysis was also extended to include the current ineffective practices which should be subject to further study and research in order to confirm the above stated conclusions. 


\section{CONCLUSIONS AND RECOMMENDATIONS}

Inadequacies in the ITE program were uncovered in the preceeding chapter. This chapter will provide a statement of the final conclusion in evaluating the ITE program supplemented with remedial recommendations to eliminate the existing deficiencies and further improve the effectiveness of the program.

\section{Conclusions}

The mission of this thesis was accomplished by exploring the inadequacies encountered in the ITE program. The ITE program was found to be deficient in several ways, some of which were due to an inadequate treatment of items such as school route map, terminology and priority system, and others were due to items not considered at alI such as portable school signs, funding, warrants, raised legends and variable message signs. In addition, the ITE has failed to delete the ineffective practices like speed limit signs with flashing beacons, speed limit signs with flags and speed bumps, etc.

The success of school pedestrian crossing protection programs relies heavily upon strict adherence to uniform practices and procedures in warranting the appropriate standard traffic control devices, as well as the enforcement of traffic regulations. For this reason, conformance to the MUTCD and coordination of joint efforts between law enforcement agencies and other responsible units are very essential and highly recommended. 


\section{Recommendations}

Improvement of the ITE program can be achieved through the implementation of the following proposed recommendations:

1. The introduction of the ITE program be revised to increase emphasis on the importance of understanding by the public and children, in particular, of traffic control devices and other protective measures utilized at or near school crossings.

2. The school route plan be modified to include other languages as deemed necessary for the convenience of non-English. speaking residents within the school boundary.

3. Terminology used in the ITE program, specificaIly, adequate gaps and blockades be defined in advance of its use.

4. Appendix B of the ITE program be incorporated into the body of Step 3 to include signalized locations together with those unsignalized, thus better integrating the intended message.

5. The ITE program be supplemented with criteria for selecting the appropriate traffic control devices best suited for a particular situation. Illustrative problems with their proper solutions are also encouraged to maintain consistent uniformity in judgment practiced by the traffic engineers.

6. Priority system in dealing with hazards be organized in the ITE program, thus assisting the school traffic safety committee in this responsibility.

7. The ITE program be modified to include a statement by which the use of portable school signs are ruled out as indicated through most of the other programs discussed in this thesis. 
8. The identification of funding sources for school safety programs be included in the ITE program.

9. Warrants for the installation of any traffic control device be established in the ITE program. Examples of these warrants are presented in Chapter III under FederaI, Iocal and misceIIaneous programs.

10. The use of raised "school" pavement legend with special lane markers be considered by the ITE.

11. The "variable message signs" be taken into consideration by the ITE.

12. The ITE program be revised to include a statement by which all traffic control measures proven to be ineffective are removed and replaced by effective devices. Examples of these ineffective measures are all pointed out in Chapter IV.

The ITE program has provided valuable information as weII as methods and procedures. However, there are a number of deficiencies which have been discovered and previously identified. This paper has listed several useful suggestions which can be incorporated into the ITE program to improve its effectiveness. 


\section{BIBLIOGRAPHY}

\section{References Cited}

1. "A Program for School Crossing Protection," Institute of Transportation (previously Traffic) Engineers, Recommended Practice of the ITE, Washington, D.C., 1962.

2. Cohen, Martin A., "One Child Dead, 17 Injured-Some SeriousIy," Redbook Magazine, 1975.

3. "Manual on Uniform Traffic Control Devices," United States Department of Transportation - Federal Highway Administration, U. S. Government Printing, Washington, D.C., 1971.

4. "Official Rulings on Requests for Interpretation, Changes, and Experimentation for the Manual on Uniform Traffic Contro1 Devices," Volume VI, United States Department of Transportation - Federal Highway Administration, Washington, D.C., 1975.

5. Zegeer, C. V., "The Effectiveness of School Signs with Flashing Beacons in Reducing Vehicle Speeds," Kentucky Bureau of Highways, Research Report 429, Lexington, 1975.

6. "School Crossing Manual," State of New Mexico, Department of Highways, Traffic Services Section, Albuquerque, 1973.

7. "Traffic Manua1," State of California, Department of Highways, Sacramento, 1975 .

8. "Proposed Warrants for the Installation of Traffic Control Devices in Schools," California Traffic Control Devices Committee, League of California Cities, Sacramento, 1969.

9. "School Traffic Engineering Program for Safety," Highway Safety Project, City of Los Angeles, 1972.

10. "Criteria for Assignment of Adult Guard," City of Seattle, Department of Engineering, 1973.

11. "School Speed Limit, Experimental Sign Program," City of Seattle, Department of Engineering, Traffic and Transportation Division, 1974.

12. "Effectiveness of Flashing Yellow Signals at School Zone," City of Los Angeles, Department of Traffic, Bureau of Traffic Research, Staff Report No. 39.07, 1969. 
13. Martini, Mario J., City of Portland, Letter to A. Reed Gibby, ITE Committee Chairman of $4 \mathrm{~A}-1,1975$.

14. Herms, Bruce Fo, "Pedestrian Crosswalk Study," City of San Diego, California, Project PS 69-2-001, 1970.

15. Grady, James 0., "Safe Route for City Pupils are Guarded by Variable Message Signs, Rural and Urban Roads," City of Arvada, Colorado, Department of Transportation and Traffic, 1975.

16. Allen, C. D. and L。 B. Walsh, "A Bumpy Road Ahead?" Traffic Engineering, Vol. 45, No. 10, 1975.

17. Reiss, Martin L. and H. Douglas Robertson, "School Trip Safety and the Traffic Engineer," United States Department of Transportation - Federal Highway Administration, Washington, D.C., 1970 .

18. "School Crossing Manual," Cedar Rapids School Crossing Safety Committee, Cedar Rapids Area, Cedar Rapids, Iowa, 1974.

\section{Other References}

Buerwald, John E., Traffic Engineering Handbook, third edition, Institute of Transportation Engineers, 1965.

"Guide to a School Pedestrian Safety Program," Automotive Safety Foundation, 1965.

"Manual on School Crossing Control," Des Moines Traffic Safety Committee, Des Moines, Iowa, 1975.

"Manual on Uniform Traffic Control Devices," State of Washington, Department of Highway, Resolution No. 2490, Order No. 132, 1972.

"Policies and Practices for School Safety Patrols," National Commission on Safety Education, National Education Association, 1958.

Sessions, Gordon M., Traffic Devices: Historical Aspects Thereof, Institute of Transportation Engineers, Washington, D.C., 1971. 